\title{
TINJAUAN KEPUASAN PELANGGAN TERHADAP KUALITAS PELAYANAN PARKIR BASEMENT DI PUSAT PERBELANJAAN BANDUNG SUPERMALL
}

\author{
Tan Lie Ing', Arie Hadian Yanuardi ${ }^{2}$ \\ 1, 2 Jurusan Teknik Sipil, Universitas Kristen Maranatha \\ J1. Prof. drg. Soeria Sumantri MPH. No. 65, Bandung, 40164 \\ telp. (022) 2012186, fax. (022) 2017622 \\ E-mail : lieing.tan@gmail.com
}

\begin{abstract}
ABSTRAK
Pusat perbelanjaan dengan konsep one stop shopping selalu menyediakan area parkir yang cukup luas pada lahannya karena konsumen dalam jumlah besar sangat tertarik untuk berkunjung ke tempat tersebut. Oleh karena itu para pengelola parkir di pusat perbelanjaan berusaha untuk menciptakan kualitas pelayanan parkir terbaiknya agar para pelanggan tetap berkunjung dan berbelanja di pusat perbelanjaan tersebut. Sebuah studi menyatakan bahwa daerah yang memiliki tempat parkir yang aman, nyaman, dan murah lebih mampu untuk mempertahankan kehadirannya. Untuk itu perlu adanya tinjauan kepuasan pelanggan terhadap kualitas pelayanan parkir yang diberikan. Penelitian ini berupa survei kepada pengunjung di pusat perbelanjaan Bandung Supermall yang menggunakan jasa penyedia parkir. Pengunjung pusat perbelanjaan diminta pendapatnya mengenai kualitas pelayanan parkir yang berupa kemudahan parkir, kinerja petugas parkir, kinerja geometrik ruang parkir, keamanan, kenyamanan, dan kesesuaian tarif parkir. Hasil penelitian menunjukkan bahwa pelanggan pada umumnya merasa puas dengan kualitas pelayanan yang diberikan oleh pengelola parkir di pusat perbelanjaan tersebut.
\end{abstract}

Kata Kunci: Pelanggan, Pusat perbelanjaan, Parkir.

\begin{abstract}
One stop shopping mall concept always provides the parking area in order that a lot of customers will come. Therefore, the parking management officer in shopping mall have to make the best quality of parking. A study express that the save, comfortable, and cheap parking area will sustain. An evaluation of the satisfaction customers to the quality of parking needs to be done. This research conduct a survey to the customers at Bandung Supermall that have the parking provider. The customers has questioned regarding the quality of the parking provider such as the available parking area, performance of parking officer, performance of geometric parking, save, comfortable, suitable of parking fee. The result shows that the customers will usually satisfy with the quality of the parking provider at the shopping mall.
\end{abstract}

Keywords: Customer, Shopping mall, Parking.

\section{PENDAHULUAN}

Bandung Supermall (BSM) merupakan pusat perbelanjaan dengan konsep one stop shopping artinya setiap yang datang berbelanja bisa sekaligus memenuhi kebutuhan pangan, sandang dan hiburan. BSM memiliki sarana hiburan seperti arena fantasi mini yang diduplikasi dari Dunia Fantasi Ancol, ruang bioskop terbesar di Bandung, ditambah dengan sarana olah raga seperti bowling dan bilyar. 
Hal ini tentunya akan memiliki daya tarik tersendiri dan secara tidak langsung akan mengundang banyak pengunjung, dan sekaligus akan menyebabkan bertambahnya permintaan akan fasilitas parkir. Fasilitas parkir yang telah tersedia dan kualitas pelayanannya menjadi salah satu ukuran kepuasan pelanggan yang berkunjung ke pusat perbelanjaan tersebut. Tujuan penelitian adalah untuk mengetahui fasilitas dan pelayanan parkir yang sudah tersedia terhadap kepuasan pelanggan.

\section{STUDI LITERATUR}

\subsection{Definisi Parkir}

Fasilitas parkir didefinisikan sebagai tempat khusus bagi kendaraan untuk berhenti demi keselamatan. Parkir mempunyai tujuan baik yaitu memungkinkan akses yang mudah. Jika parkir terlalu jauh dari tempat tujuan, orang akan cenderung beralih pergi ketempat lain sehingga tujuan utama adalah agar lokasi parkir sedekat mungkin dengan tujuan perjalanan.

\subsection{Ketentuan Umum}

Fasilitas parkir secara garis besar dibagi 2 (dua) macam yaitu: fasilitas parkir di jalan (on-street parking) dan fasilitas parkir di luar jalan (off-street parking).

Fasilitas parkir di jalan (on-street parking) adalah fasilitas parkir yang menggunakan tepi jalan sebagai ruang parkirnya, sedangkan fasilitas parkir di luar jalan (off-street parking) adalah fasilitas parkir kendaraan di luar tepi jalan umum, yang dibuat khusus sebagai penunjang kegiatan, berupa pelataran parkir dan atau gedung parkir.

\subsection{Satuan Ruang Parkir (SRP)}

Menurut Pedoman Teknis Penyelenggaraan Fasilitas Parkir Direktorat Jenderal Perhubungan Darat (1998), Satuan Ruang Parkir (SRP) adalah ukuran luas efektif untuk meletakkan kendaraan (mobil penumpang, bus/truk atau sepeda motor) termasuk ruang bebas dan lebar bukaan pintu. Dalam penentuan besarnya satuan ruang parkir tergantung dari beberapa parameter-parameter sebagai berikut:

$$
\begin{aligned}
& \text { SRP4 }=\mathrm{f}\{\mathrm{D}, \mathrm{Ls}, \mathrm{Lm}, \mathrm{Lp}\} \\
& \mathrm{SRP} 2=\mathrm{f}\{\mathrm{D}, \mathrm{Ls}, \mathrm{Lm}\}
\end{aligned}
$$

dengan: SRP4 = Satuan ruang parkir untuk kendaraan roda empat

SRP2 = Satuan ruang parkir untuk kendaraan roda dua

D $=$ Dimensi kendaraan standar

Ls $\quad=$ Ruang kebebasan samping arah lateral

$\mathrm{Lm} \quad=$ Ruang kebebasan samping arah membujur

$\mathrm{Lp} \quad=$ Lebar bukaan pintu 


\subsubsection{Dimensi Kendaraan Standar untuk Mobil Penumpang}

Seiring dengan kemajuan teknologi dari tahun ke tahun terus mengalami kemajuan, kecenderungan bagi produsen kendaraan bermotor meluncurkan berbagai jenis model dan ukuran kendaraan, sehingga ukuran kendaraan yang ada menjadi beraneka ragam, tentunya hal ini menyebabkan perbedaan mengenai penentuan daya tampung suatu lahan parkir, oleh karena itu penentuan dimensi kendaraan standar menjadi sangat penting, supaya dalam perencanaan fasilitas parkir ada suatu ketentuan baku yang dijadikan sebagai acuan.

Gambar 1 merupakan dimensi kendaraan standar untuk mobil penumpang menurut Direktorat Jenderal Perhubungan Darat (1998).
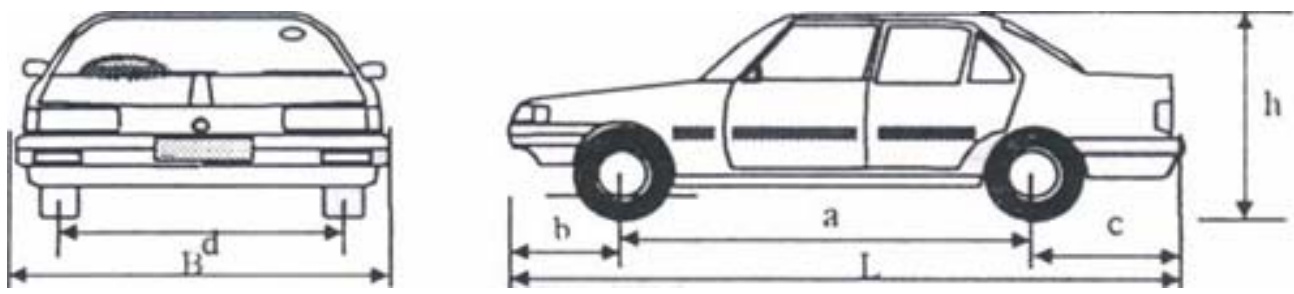

Sumber: Pedoman Perencanaan dan Pengoperasian Fasilitas Parkir Direktorat Jenderal Perhubungan Darat, 1998

Keterangan:

$\mathrm{a}=$ Jarak gandar $\mathrm{h}=$ Tinggi total

$\mathrm{b}=$ Depan tergantung (front overhang) $\mathrm{B}=$ Lebar total

$\mathrm{c}=$ Belakang tergantung (rear overhang) $\mathrm{L}=$ Panjang total

$\mathrm{d}=$ Lebar jejak

\section{Gambar 1. Dimensi Kendaraan Standar untuk Mobil Penumpang}

\subsubsection{Ruang Bebas Kendaraan Parkir}

Ruang bebas kendaraan parkir diberikan pada arah lateral dan longitudinal kendaraan. Ruang bebas kendaraan arah lateral ditetapkan pada saat posisi pintu kendaraan dibuka, yang diukur dari ujung paling luar pintu ke badan kendaraan parkir yang ada disamping. Jarak bebas arah lateral diambil $5 \mathrm{~cm}$ dan jarak bebas arah longitudinal sebesar $30 \mathrm{~cm}$.

\subsubsection{Lebar Bukaan Pintu Parkir}

Ukuran lebar bukaan pintu merupakan fungsi karakteristik pemakai kendaraan yang memanfaatkan fasilitas parkir. Lebar bukaan pintu kendaraan karyawan kantor akan berbeda dengan lebar bukaan pintu kendaraan pengunjung pusat kegiatan perbelanjaan. Dalam hal 
ini, karakteristik pengguna kendaraan yang memanfaatkan fasilitas parkir dipilih menjadi 3 (tiga) golongan seperti yang ditunjukkan pada Tabel 1.

Tabel 1. Lebar Bukaan Pintu Kendaraan

\begin{tabular}{lll}
\hline Jenis Bukaan Pintu & $\begin{array}{l}\text { Pengguna dan/atau Peruntukan } \\
\text { Fasilitas Parkir }\end{array}$ & Golongan \\
\hline Pintu depan/belakang terbuka & $\begin{array}{l}\text { 1. Karyawan/pekerja kantor } \\
\text { 2. Tamu/pengunjung pusat kegiatan } \\
\text { perkantoran, perdagangan, } \\
\text { pemerintahan, universitas }\end{array}$ & I \\
& $\begin{array}{l}\text { 1.Pengunjung tempat olahraga, pusat } \\
\text { hiburan/rekreasi, hotel, pusat } \\
\text { perdagangan eceran/swalayan, rumah } \\
\text { sakit, bioskop }\end{array}$ & II \\
\hline $\begin{array}{l}\text { Pintu depan/belakang } \\
\text { terbuka penuh } 75 \mathrm{~cm}\end{array}$ & & \\
& & $\mathrm{III}$ \\
\hline $\begin{array}{l}\text { Pintu depan terbuka penuh dan } \\
\text { ditambah untuk pergerakan } \\
\text { kursi roda }\end{array}$ & 1.Orang Cacat & \\
\hline
\end{tabular}

Sumber: Pedoman Perencanaan dan Pengoperasian Fasilitas Parkir Direktorat Jenderal Perhubungan Darat, 1998

Berdasarkan pertimbangan dari Tabel 1, Satuan Ruang Parkir (SRP) dapat dibagi atas tiga jenis kendaraan, dan berdasarkan penentuan SRP untuk mobil penumpang diklasifikasikan menjadi tiga golongan, seperti tercantum dalam Tabel 2.

Tabel 2. Penentuan Satuan Ruang Parkir (SRP) dalam satuan m

\begin{tabular}{lc}
\hline \multicolumn{1}{c}{ Jenis Kendaraan } & Satuan Ruang Parkir (SRP) \\
\hline 1. a. Mobil penumpang untuk golongan I & $2,30 \times 5,00$ \\
b. Mobil penumpang untuk golongan II & $2,50 \times 5,00$ \\
c. Mobil penumpang untuk golongan III & $3,40 \times 5,00$ \\
2. Bus/truk & $3,00 \times 12,50$ \\
3. Sepeda motor & $0,75 \times 2,00$ \\
\hline
\end{tabular}

Sumber: Pedoman Perencanaan dan Pengoperasian Fasilitas Parkir Direktorat Jenderal Perhubungan Darat (1998).

Keterangan:

$\mathrm{B}=$ Lebar total kendaraan $\quad \mathrm{R}=$ Jarak bebas arah lateral

$\mathrm{L}=$ Panjang total $\quad \mathrm{Bp}=\operatorname{Lebar} \mathrm{SRP}(\mathrm{B}+\mathrm{O}+\mathrm{R})$

$\mathrm{O}=$ Lebar bukaan pintu $\quad \mathrm{Lp}=$ Panjang SRP $(\mathrm{L}+\mathrm{a} 1+\mathrm{a} 2)$

a1,a2 = Jarak bebas 


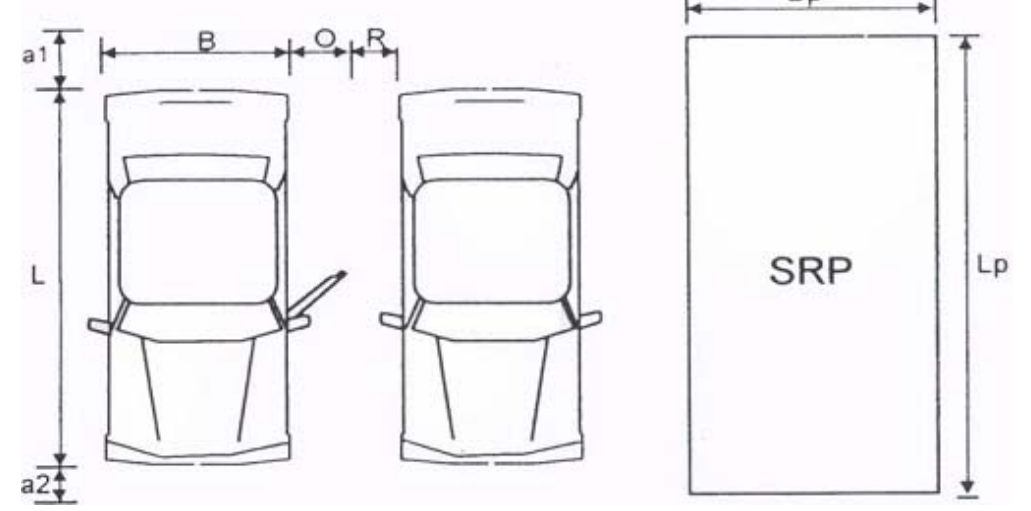

Gambar 2. Satuan Ruang Parkir (SRP) untuk Mobil Penumpang

Dimensi SRP untuk mobil penumpang diperlihatkan pada Tabel 3.

Tabel 3. Dimensi SRP Mobil Penumpang dalam Satuan cm

\begin{tabular}{lccc}
\hline & Golongan I & Golongan II & Golongan III \\
\hline $\mathrm{B}$ & 170 & 170 & 170 \\
\hline $\mathrm{O}$ & 55 & 75 & 80 \\
\hline $\mathrm{R}$ & 5 & 5 & 50 \\
\hline $\mathrm{a} 1$ & 10 & 10 & 10 \\
\hline $\mathrm{L}$ & 470 & 470 & 470 \\
\hline $\mathrm{a} 2$ & 20 & 20 & 20 \\
\hline $\mathrm{Bp}$ & 230 & 250 & 300 \\
\hline $\mathrm{Lp}$ & 500 & 500 & 500 \\
\hline
\end{tabular}

Sumber: Pedoman Perencanaan dan Pengoperasian Fasilitas Parkir Direktorat Jenderal Perhubungan Darat, 1998

\subsection{Analisis Statistik}

\subsubsection{Variabel}

Variabel adalah sesuatu hal yang berbentuk apa saja yang ditetapkan oleh peneliti untuk dipelajari sehingga diperoleh informasi tentang hal tersebut, kemudian ditarik kesimpulannya.

Berdasarkan pengertian tersebut, maka variabel dapat dibagi menurut hubungan antara satu variabel dengan variabel lain menjadi variabel bebas, variabel terikat, variabel intervening, variabel kontrol, dan variabel moderator.

Untuk penelitian yang bersifat sosial dikenal dua macam variabel (Singarimbun, 1995), yaitu: variabel kategorikal dan variabel bersambung. 


\subsubsection{Skala Pengukuran}

Skala pengukuran merupakan kesepakatan yang digunakan sebagai acuan untuk menentukan panjang pendeknya interval yang ada dalam alat ukur, sehingga alat ukur tersebut bila digunakan dalam pengukuran dapat menghasilkan data kuantitatif. Singarimbun (1995) membagi skala pengukuran menjadi empat macam, yaitu: skala nominal, skala ordinal, skala interval, dan skala rasio.

\subsubsection{Uji Validitas}

Kevaliditasan sebuah instrumen penelitian tersebut perlu diuji disamping juga perlunya pengujian reliabilitasnya. Instrumen yang valid berarti alat ukur yang digunakan untuk memperoleh data itu valid sehingga dapat digunakan untuk mengukur apa yang hendak diukur.

Sugiyono (2002) membagi pengujian validitas menjadi: Validitas Konstruksi, Validitas Isi dan Validitas Eksternal

Singarimbun (1995) menambahkan beberapa macam validitas lagi selain yang tertera di atas, yaitu: Validitas Prediktif, Validitas Budaya dan Validitas Rupa

Banyak rumus yang dapat dipakai untuk mengetahui nilai validitas suatu penelitian, tergantung korelasi yang dikehendaki dari penelitian tersebut, diantaranya adalah rumus Product Moment Pearson:

$$
\mathrm{r}_{\mathrm{XY}}=\frac{\mathrm{N} \sum \mathrm{XY}-\sum \mathrm{X} \sum \mathrm{Y}}{\sqrt{\left\{\mathrm{N} \sum \mathrm{X}^{2}-\left(\sum \mathrm{X}\right)^{2}\right\}\left\{\mathrm{N} \sum \mathrm{Y}^{2}-\left(\sum \mathrm{Y}\right)^{2}\right\}}}
$$

dengan: $\mathrm{N}=$ Jumlah responden, $\mathrm{X}=$ Skor variabel $\mathrm{X}, \mathrm{Y}=$ Skor variabel $\mathrm{Y}$

\subsubsection{Uji Reliabilitas}

Reliabilitas adalah indeks yang menunjukkan sejauh mana suatu alat pengukur dapat dipercaya atau diandalkan. Sugiyono (2002) mengklasifikasikan teknikteknik yang bisa dilakukan dalam pengujian reliabilitas, diantaranya adalah: Test-Retest, Pengujian dengan membuat dua instrumen yang ekivalen, Teknik Gabungan dan Internal Konsistensi

Rumusan yang dipakai untuk penelitian ini mengambil dari rumusan yang dikemukakan oleh Alfa Cronbach dan menggunakan penskoran pada data dari 1 sampai dengan 5 . 
Rumus-rumus lain hanya bisa menggunakan penskoran 1 dan 0 saja.

$$
\mathrm{r}_{11}=\left\{\frac{\mathrm{k}}{\mathrm{k}-1}\right\}\left\{1-\frac{\sum \sigma_{\mathrm{b}}{ }^{2}}{\sigma_{1}^{2}}\right\}
$$

dimana:

$$
\begin{array}{ll}
\mathrm{r}_{11} & =\text { Reliabilitas konsumen } \\
\mathrm{k} & =\text { Banyaknya butir pertanyaan atau banyaknya soal } \\
\sum \sigma_{\mathrm{b}}{ }^{2} & =\text { Jumlah varians butir } \\
\sigma_{1}{ }^{2} & =\text { Varians total }
\end{array}
$$

\subsubsection{Uji Normalitas}

Untuk menguji normalitas digunakan rumus chi square atau chi kuadrat. Rumusan umum chi kuadrat seperti yang tertera dibawah ini:

$$
\mathrm{X}^{2}=\frac{\sum\left(\mathrm{f}_{\mathrm{o}}-\mathrm{f}_{\mathrm{e}}\right)^{2}}{\mathrm{f}_{\mathrm{e}}}
$$

dimana:

$$
\begin{array}{ll}
\mathrm{X}_{2} & =\text { Chi Kuadrat } \\
\mathrm{f}_{\mathrm{o}} & =\text { Frekuensi hasil observasi dari sampel penelitian } \\
\mathrm{f}_{\mathrm{e}} & =\text { Frekuensi yang diharapkan pada populasi penelitian }
\end{array}
$$

\section{METODOLOGI PENELITIAN}

\subsection{Pengumpulan Data}

Data primer berupa wawancara kepada pengguna jasa parkir sebagai responden dan data sekunder diperoleh dengan menghubungi instansi-instansi terkait yang berhubungan dengan masalah perparkiran.

\subsection{Perencanaan Angket}

Perencanaan angket harus disesuaikan dengan tujuan penelitian. Tujuan penelitian adalah mengetahui tingkat kepuasan pelanggan terhadap kualitas pelayanan parkir yang sudah ada. Angket berisi pertanyaan-pertanyaan yang terbagi atas tiga kategori terdiri dari : Data responden, Kemudahan parkir, dan Kualitas pelayanan parkir

\subsection{Penentuan Jumlah Sampel}

Untuk suatu sampel yang besar paling sedikit harus diambil 30 data responden yang diambil secara acak (Singarimbun, 1995). Untuk pengambilan sampel digunakan metode 
Nonprobability Sampling yaitu teknik yang tidak memberi peluang/kesempatan sama bagi setiap unsur anggota populasi untuk dipilih menjadi sampel.

Pada penelitian ini digunakan sampel sebanyak 50 sampel untuk lokasi penelitian dengan pertimbangan adanya angket yang tidak terisi sempurna. Angket yang benar-benar terisi dengan sempurna berjumlah 45 sampel untuk lokasi penelitian yang kemudian akan dilakukan pengolahan data.

\subsection{Materi Penelitian}

Materi penelitian berupa kumpulan data yang akan digunakan sebagai bahan analisis yang diwujudkan dalam bentuk angket kepada responden (data primer), kumpulan data dari instansi yang terkait serta studi literatur (data sekunder). Materi penelitian untuk responden terdiri dari beberapa bagian, yaitu Bagian A: Data Responden, Bagian B: Kemudahan Parkir, dan Bagian C: Pendapat Responden Tentang Kualitas Pelayanan Parkir Setempat.

\subsubsection{Data Responden (Bagian A)}

Pada bagian ini hanya terdiri dari dua pertanyaan/variabel yang menyangkut identitas responden secara garis besar. Pertanyaan/variabel tersebut berupa pilihan yang dimaksudkan untuk memudahkan responden mengisi angket. Selanjutnya untuk memudahkan dalam pengolahan data maka pertanyaan/variabel tersebut dikodekan dengan:

a. Nama responden $=$ Tanpa kode

b. Frekuensi berkunjung ke lokasi $=$ Profil 1

\subsubsection{Pendapat Responden Tentang Kemudahan Parkir Setempat (BagianB)}

Pada bagian B dari angket, responden diharapkan memberikan jawaban sesuai dengan pengalamannya. Pada bagian ini hanya terdiri dari tiga pertanyaan dimana penentuan skornya menggunakan skala Likert. Pilihan jawabannya dimulai dari Selalu, Sering, Kadangkadang, Pernah, dan Tidak Pernah. Dengan penskoran sebagai berikut:

Untuk no. 1-2 : Dari skor 1 untuk jawaban selalu sampai dengan skor 5 untuk jawaban tidak pernah

Pada analisis berikutnya skor mempunyai arti: Skor $5=$ Sangat Bagus, Skor $4=$ Bagus, Skor 3 = Sedang, Skor 2 = Jelek, Skor 1 = Sangat Jelek

Untuk analisis data selanjutnya, setiap variabel diberikan pengkodean tertentu, yaitu yang tertera pada Tabel 4. 
Tabel 4. Pengkodean Variabel Kemudahan Parkir

\begin{tabular}{cccc}
\hline No & Variabel & Keterangan & Elemen yang diteliti \\
\hline 1 & B1 & $\begin{array}{c}\text { Sering tidaknya keluar area parkir karena } \\
\text { tidak mendapatkan tempat parkir }\end{array}$ & Kemudahan Parkir \\
\hline 2 & B2 & $\begin{array}{c}\text { Sering tidaknya berputar-putar dalam area } \\
\text { parkir untuk mencari tempat parkir }\end{array}$ & \\
\hline
\end{tabular}

Setiap butir pertanyaan bagian B pada angket merupakan frekuensi kepuasan pelanggan terhadap pelayanan yang diberikan oleh pengelola parkir.

\subsubsection{Pendapat Responden Tentang Kinerja dan Kualitas Pelayanan Parkir Setempat (Bagian C)}

Keseluruhan pertanyaan tersebut berjumlah 13 (tiga belas) butir dengan pilihan jawaban dan penentuan skor menggunakan skala Likert. Pilihan jawaban dimulai dari sangat setuju, setuju, tidak berpendapat, tidak setuju, hingga sangat tidak setuju dengan penskoran dari 5 untuk sangat setuju sampai dengan skor 1 untuk jawaban sangat tidak setuju.

Meskipun bagian $\mathrm{C}$ ini menggunakan skala yang sama dalam penentuan skor dengan bagian $\mathrm{B}$, tetapi analisisnya dipisahkan, karena bagian $\mathrm{C}$ ini memiliki pilihan jawaban yang berbeda dengan bagian B. Arti skor sama dengan bagian B. Untuk analisis data selanjutnya, setiap variabel diberikan pengkodean tertentu, yaitu yang tertera pada Tabel 4 .

\subsection{Lokasi dan Waktu Penelitian}

Penelitian dilakukan dengan mengambil tempat di pusat perbelanjaan terbesar yaitu Bandung Supermall (BSM). Pengambilan data primer dilakukan pada hari Sabtu tanggal 11 Desember 2004 pada saat jam puncak berkunjung yaitu pada pukul 16.00 - 21.00 WIB, sehingga hasil yang diharapkan merupakan gambaran kualitas pelayanan parkir terburuk yang diberikan oleh penyedia jasa parkir.

Tabel 5. Pengkodean Variabel Kinerja dan Kualitas Pelayanan Parkir

\begin{tabular}{cccc}
\hline No & Variabel & Keterangan & $\begin{array}{c}\text { Elemen yang } \\
\text { diteliti }\end{array}$ \\
\hline 3 & C3 & $\begin{array}{c}\text { Kecekatan petugas parkir lapangan dalam } \\
\text { mencarikan tempat parkir yang kosong }\end{array}$ & $\begin{array}{c}\text { Kinerja Petugas } \\
\text { Parkir }\end{array}$ \\
\hline 4 & C4 & $\begin{array}{c}\text { Kecekatan petugas parkir lapangan untuk } \\
\text { memandu memarkirkan kendaraan }\end{array}$ & \\
\hline
\end{tabular}




\begin{tabular}{|c|c|c|c|}
\hline \multicolumn{4}{|c|}{ Tabel 4. (lanjutan) } \\
\hline 5 & $\mathrm{C5}$ & Kondisi satuan ruang parkir & $\begin{array}{c}\text { Geometrik ruang } \\
\text { parkir }\end{array}$ \\
\hline 6 & C6 & Kondisi Lebar pintu masuk & \\
\hline 7 & $\mathrm{C} 7$ & Kondisi Lebar jalur gang & \\
\hline 8 & $\mathrm{C} 8$ & Karcis parkir sebagai identitas kendaraan & Keamanan \\
\hline 9 & C9 & Pemeriksaan karcis parkir di pintu keluar & \\
\hline 10 & $\mathrm{C} 10$ & Keamanan berjalan di area parkir & \\
\hline 11 & $\mathrm{C} 11$ & No lokasi parkir & \\
\hline 12 & $\mathrm{C} 12$ & Kondisi sirkulasi udara & Kenyamanan \\
\hline 13 & C13 & Kondisi penerangan & \\
\hline 14 & $\mathrm{C} 14$ & Jarak berjalan menuju lokasi & Tarif parkir \\
\hline 15 & $\mathrm{C} 15$ & Kesesuaian tarif parkir & \\
\hline
\end{tabular}

\section{PENGOLAHAN DAN ANALISIS DATA}

\subsection{Pengujian Validitas}

Data yang dipakai dalam pengolahan untuk pengujian validitas sebanyak tiga puluh data. Tidak ada batasan tertentu dalam menentukan jumlah data yang akan diuji kevalidannya. Data-data yang tidak lengkap diisi oleh responden tidak akan diikutsertakan dalam analisis selanjutnya. Ada beberapa hal penting yang terkait dengan pembacaan hasil pengujian validitas dengan menggunakan program SPSS 11, yaitu:

1. Arti angka korelasi

a. Berkenaan dengan besaran angka. Angka korelasi berkisar pada 0 (tidak ada korelasi sama sekali) sampai dengan 1 (korelasi sempurna). Angka korelasi diatas 0,5 menunjukkan korelasi cukup kuat, sedangkan di bawah 0,5 korelasinya lemah.

b. Berkaitan dengan tanda korelasi. Tanda negatif (-) pada output menunjukkan adanya arah yang berlawanan, sedangkan tanda positif $(+)$ menunjukkan arah yang sama.

2. Hipotesis

a. $\mathrm{H}_{0}=$ Tidak ada hubungan (korelasi) antara dua variabel atau angka korelasi 0

b. $\mathrm{H}=$ Ada hubungan (korelasi) antara dua variabel atau angka korelasi tidak 0

3. Pengambilan keputusan

a. Berdasarkan Probabilitas

Jika probabilitas $>0,05$, maka $\mathrm{H} 0$ diterima

Jika probabilitas $<0,05$, maka $\mathrm{H} 0$ ditolak 
b. Berdasarkan tanda bintang (*) yang diberikan SPSS Signifikansi tidaknya korelasi dua variabel dapat dilihat dari tanda bintang (*) pada pasangan data yang dikorelasikan

c. Berdasarkan nilai rx,y dari Korelasi Pearson (Pearson Correlation)

Jika rx,y > r tabel, maka H0 ditolak

Jika rx,y $<$ r tabel, maka H0 diterima

\subsubsection{Pengujian Validitas Pendapat Responden Tentang Kemudahan Parkir}

Untuk semua pertanyaan yang diberikan kepada responden tentang kemudahan parkir tidak ada yang diubah, ditambah, dikurangi, ataupun dihilangkan karena nilai validannya memadai. Adapun langkah perhitungan seperti tertera dibawah ini:

1. Input data

2. Hasil perhitungan pengujian validitas untuk pendapat responden tentang kemudahan parkir, dengan menggunakan program SPSS 11 seperti tertera pada Tabel 6.

Tabel 6. Validitas Pendapat Responden Tentang Kemudahan Parkir

\begin{tabular}{ccc}
\hline & Nilai Terendah & Nilai Tertinggi \\
\hline Korelasi Pearson & 0,837 & 0,858 \\
\hline Tes Dua Ekor (sig. (2-tailed)) & 0,000 & 0,000 \\
\hline
\end{tabular}

3. Analisis

a. Berdasarkan probabilitas

Terlihat dari tabel di atas, nilai signifikan tes dua ekor (sig 2-tailed) kurang dari 0,05, hal tersebut berarti $\mathrm{H} 0$ ditolak dan $\mathrm{H}$ diterima.

b. Berdasarkan nilai rx,y

Degree of freedom $(\mathrm{df})=\mathrm{n}-2=30-2=28$

Interval kepercayaan $95 \%$ atau á $=0,05$

Didapatkan nilai $r$ kritik $=0,361$

Semua nilai korelasi Pearson yang terdapat dari perhitungan $>r$ kritik. Hal tersebut menyatakan bahwa $\mathrm{H} 0$ ditolak dan $\mathrm{H}$ diterima.

Berdasarkan paparan di atas menyatakan bahwa hipotesis $\mathrm{H}$ diterima (ada hubungan antara dua variabel). Hal ini berarti semua variabel saling berhubungan antara satu dengan yang lainnya. 


\subsubsection{Pengujian Validitas Pendapat Responden Tentang Kinerja dan Kualitas Pelayanan Parkir}

Untuk semua pertanyaan yang diberikan kepada responden tentang kinerja dan kualitas pelayanan parkir tidak ada yang diubah, ditambah, dikurangi, ataupun dihilangkan karena nilai validannya memadai.

Adapun langkah perhitungan seperti tertera dibawah ini:

1. Input data

2. Hasil perhitungan pengujian validitas untuk pendapat responden tentang kualitas pelayanan parkir, dengan menggunakan program SPSS 11 seperti tertera pada Tabel 7.

Tabel 7. Validitas Pendapat Responden Tentang Kinerja dan Kualitas Pelayanan Parkir

\begin{tabular}{lcc}
\hline & Nilai Terendah & Nilai Tertinggi \\
\hline Korelasi Pearson & 0,529 & 0,777 \\
\hline Tes Dua Ekor (sig. (2-tailed)) & 0,000 & 0,003 \\
\hline
\end{tabular}

3. Analisis

a. Berdasarkan probabilitas

Terlihat dari tabel di atas, nilai signifikan tes dua ekor (sig 2-tailed) kurang dari 0,05, hal tersebut berarti H0 ditolak dan $\mathrm{H}$ diterima.

b. Berdasarkan nilai rx,y

Degree of freedom $(\mathrm{df})=\mathrm{n}-2=30-2=28$

Interval kepercayaan $95 \%$ atau $\alpha=0,05$

Didapatkan nilai $r$ kritik $=0,361$

Semua nilai korelasi Pearson yang terdapat dari perhitungan $>\mathrm{r}$ kritik. Hal tersebut menyatakan bahwa $\mathrm{H}_{0}$ ditolak dan $\mathrm{H}$ diterima.

\subsection{Statistik Deskriptif}

a. Statistik Deskriptif Data Responden (Bagian A)

Variabel yang diolah hanya satu buah sesuai dengan jumlah pertanyaan yang diajukan pada bagian A pada angket. Berdasarkan analisis frekuensi dari empat puluh lima 
responden, ternyata sebagian besar responden jarang (53,33\%) berkunjung ke lokasi penelitian, seperti yang terlihat pada Tabel 8 .

Tabel 8. Frekuensi Berkunjung Ke Bandung Supermall

\begin{tabular}{|c|c|c|c|c|c|}
\hline Lokasi & $\begin{array}{c}\text { Frekuensi } \\
\text { Berkunjung }\end{array}$ & $\begin{array}{c}\text { Jumlah } \\
\text { Frekuensi }\end{array}$ & $\begin{array}{c}\text { Persen } \\
(\%)\end{array}$ & $\begin{array}{c}\text { Persen } \\
\text { Valid (\%) }\end{array}$ & $\begin{array}{l}\text { Kumulatif } \\
\text { Persen(\%) }\end{array}$ \\
\hline \multirow{5}{*}{ 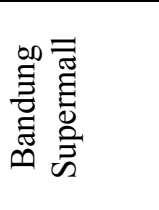 } & Baru 1-2 kali & 6 & 13,34 & 13,34 & 13,34 \\
\hline & Jarang & 24 & 53,33 & 53,33 & 66,67 \\
\hline & Sering & 10 & 22,22 & 22,22 & 88,89 \\
\hline & Sering Sekali & 5 & 11,11 & 11,11 & 100,0 \\
\hline & Total & 45 & 100,0 & 100,0 & \\
\hline
\end{tabular}

b. Statistik Deskriptif Pendapat Responden Tentang Kemudahan Parkir (Bagian B)

Untuk memudahkan pembacaan hasil pengolahan data, maka statistik deskriptifnya ditampilkan pada Tabel 9 dan Tabel 10.

Tabel 9. Sering Tidaknya Keluar Area Parkir karena

Tidak Mendapatkan Tempat Parkir (B1)

\begin{tabular}{lrrrr}
\hline & Frequency & Percent & $\begin{array}{r}\text { Valid } \\
\text { Percent }\end{array}$ & Percent \\
\hline Selalu & 9 & 20.0 & 20.0 & 20.0 \\
\hline Sering & 3 & 6.7 & 6.7 & 26.7 \\
\hline $\begin{array}{l}\text { Kadang- } \\
\text { Kadang }\end{array}$ & 7 & 15.6 & 15.6 & 42.2 \\
\hline Pernah & 11 & 24.4 & 24.4 & 66.7 \\
\hline $\begin{array}{l}\text { Tidak } \\
\text { Pernah }\end{array}$ & 15 & 33.3 & 33.3 & 100.0 \\
\hline Total & 45 & 100.0 & 100.0 & \\
\hline
\end{tabular}

Tabel 10. Sering Tidaknya Berputar-putar dalam Area Parkir untuk Mencari Tempat Parkir (B2)

\begin{tabular}{lrrrr}
\hline & Frequency & Percent & \multicolumn{2}{r}{ Calid } \\
\hline & 8 & 17.8 & 17.8 & Percent \\
\hline Selalu & 9 & 20.0 & 20.0 & 17.8 \\
\hline Sering & 9 & 20.0 & 20.0 & 57.8 \\
\hline $\begin{array}{l}\text { Kadang- } \\
\text { Kadang }\end{array}$ & 10 & 22.2 & 22.2 & 80.0 \\
\hline Pernah & 9 & 20.0 & 20.0 & 100.0 \\
\hline Tidak Pernah & 45 & 100.0 & 100.0 & \\
\hline Total & & & & \\
\hline
\end{tabular}


c. Statistik Deskriptif Pendapat Responden Tentang Kinerja dan Kualitas Pelayanan Parkir (Bagian C)

Untuk memudahkan pembacaan hasil pengolahan data, maka statistik deskriptifnya ditampilkan dalam Tabel 10 sampai dengan Tabel 22.

Jenis pertanyaan untuk kinerja dan kualitas pelayanan parkir ini yang dilambangkan oleh variabel C3-C15 dapat dilihat pada Tabel 4.

Tabel 10. Kecekatan Petugas Parkir Lapangan dalam Mencarikan Tempat Parkir yang Kosong (C3)

\begin{tabular}{lrrrr}
\hline & & & & Cumulative \\
\hline & Frequency & Percent & Valid Percent & Percent \\
\hline Tidak Setuju & 1 & 2.2 & 2.2 & 2.2 \\
\hline Tidak Berpendapat & 11 & 24.4 & 24.4 & 26.7 \\
\hline Setuju & 23 & 51.1 & 51.1 & 77.8 \\
\hline Sangat Setuju & 10 & 22.2 & 22.2 & 100.0 \\
\hline Total & 45 & 100.0 & 100.0 & \\
\hline
\end{tabular}

Tabel 11. Kecekatan Petugas Parkir Lapangan untuk Memandu Memarkirkan Kendaraan (C4)

\begin{tabular}{lrrrr}
\hline & & & & Cumulative \\
\hline & Frequency & Percent & Valid Percent & Percent \\
\hline Tidak Setuju & 3 & 6.7 & 6.7 & 6.7 \\
\hline Tidak Berpendapat & 13 & 28.9 & 28.9 & 35.6 \\
\hline Setuju & 20 & 44.4 & 44.4 & 80.0 \\
\hline Sangat Setuju & 9 & 20.0 & 20.0 & 100.0 \\
\hline Total & 45 & 100.0 & 100.0 & \\
\hline
\end{tabular}

Tabel 12. Kondisi Satuan Ruang Parkir (C5)

\begin{tabular}{lrrrr}
\hline & Frequency & Percent & $\begin{array}{r}\text { Valid } \\
\text { Percent }\end{array}$ & Percent \\
\hline $\begin{array}{l}\text { Tidak } \\
\text { Berpendapat }\end{array}$ & 10 & 22.2 & 22.2 & 22.2 \\
\hline Setuju & 26 & 57.8 & 57.8 & 80.0 \\
\hline Sangat Setuju & 9 & 20.0 & 20.0 & 100.0 \\
\hline Total & 45 & 100.0 & 100.0 & \\
\hline
\end{tabular}


Tabel 13. Kondisi Lebar Pintu Masuk (C6)

\begin{tabular}{lrrrr}
\hline & & & & Cumulative \\
\hline & Frequency & Percent & $\begin{array}{r}\text { Valid } \\
\text { Percent }\end{array}$ & Percent \\
\hline $\begin{array}{l}\text { Tidak } \\
\text { Berpendapat }\end{array}$ & 10 & 22.2 & 22.2 & 22.2 \\
\hline Setuju & 25 & 55.6 & 55.6 & 77.8 \\
\hline Sangat Setuju & 10 & 22.2 & 22.2 & 100.0 \\
\hline Total & 45 & 100.0 & 100.0 & \\
\hline
\end{tabular}

Tabel 14. Kondisi Lebar Jalur Gang (C7)

\begin{tabular}{lrrrr}
\hline & & & & Cumulative \\
\hline & Frequency & Percent & $\begin{array}{r}\text { Valid } \\
\text { Percent }\end{array}$ & Percent \\
\hline $\begin{array}{l}\text { Sangat Tidak } \\
\text { Setuju }\end{array}$ & 1 & 2.2 & 2.2 & 2.2 \\
\hline Tidak Setuju & 11 & 24.4 & 24.4 & 26.7 \\
\hline $\begin{array}{l}\text { Tidak } \\
\text { Berpendapat }\end{array}$ & 9 & 20.0 & 20.0 & 46.7 \\
\hline Setuju & 16 & 35.6 & 35.6 & 82.2 \\
\hline Sangat Setuju & 8 & 17.8 & 17.8 & 100.0 \\
\hline Total & 45 & 100.0 & 100.0 & \\
\hline
\end{tabular}

Tabel 15. Karcis Parkir Sebagai Identitas Kendaraan (C8)

\begin{tabular}{lrrrr}
\hline & Frequency & Percent & $\begin{array}{r}\text { Valid } \\
\text { Percent }\end{array}$ & Percent \\
\hline $\begin{array}{l}\text { Tidak } \\
\text { Berpendapat }\end{array}$ & 8 & 17.8 & 17.8 & 17.8 \\
\hline Setuju & 24 & 53.3 & 53.3 & 71.1 \\
\hline Sangat Setuju & 13 & 28.9 & 28.9 & 100.0 \\
\hline Total & 45 & 100.0 & 100.0 & \\
\hline
\end{tabular}

Tabel 16. Pemeriksaan Karcis Parkir di Pintu Keluar (C9)

\begin{tabular}{lrrrr}
\hline & Frequency & Percent & $\begin{array}{r}\text { Valid } \\
\text { Percent }\end{array}$ & Percent \\
\hline Tidak Setuju & 4 & 8.9 & 8.9 & 8.9 \\
\hline Tidak & 5 & 11.1 & 11.1 & 20.0 \\
Berpendapat & & & & \\
\hline Setuju & 29 & 64.4 & 64.4 & 84.4 \\
\hline Sangat Setuju & 7 & 15.6 & 15.6 & 100.0 \\
\hline Total & 45 & 100.0 & 100.0 & \\
\hline
\end{tabular}


Tabel 17. Keamanan Berjalan di Area Parkir (C10)

\begin{tabular}{lrrrr}
\hline & & & \multicolumn{2}{r}{ Cumulative } \\
\hline & Frequency & Percent & $\begin{array}{r}\text { Valid } \\
\text { Percent }\end{array}$ & Percent \\
\hline Tidak Setuju & 2 & 4.4 & 4.4 & 4.4 \\
\hline $\begin{array}{l}\text { Tidak } \\
\text { Berpendapat }\end{array}$ & 8 & 17.8 & 17.8 & 22.2 \\
\hline Setuju & 25 & 55.6 & 55.6 & 77.8 \\
\hline Sangat Setuju & 10 & 22.2 & 22.2 & 100.0 \\
\hline Total & 45 & 100.0 & 100.0 & \\
\hline
\end{tabular}

Tabel 18. No. Lokasi Parkir (C11)

\begin{tabular}{lrrrr}
\hline & Frequency & Percent & $\begin{array}{r}\text { Valid } \\
\text { Percent }\end{array}$ & Percent \\
\hline & 1 & 2.2 & 2.2 & 2.2 \\
\hline $\begin{array}{l}\text { Sangat Tidak } \\
\text { Setuju }\end{array}$ & 11 & 24.4 & 24.4 & 26.7 \\
\hline $\begin{array}{l}\text { Tidak } \\
\text { Berpendapat }\end{array}$ & & & & \\
\hline Setuju & 27 & 60.0 & 60.0 & 86.7 \\
\hline Sangat Setuju & 6 & 13.3 & 13.3 & 100.0 \\
\hline Total & 45 & 100.0 & 100.0 & \\
\hline
\end{tabular}

Tabel 19. Kondisi Sirkulasi Udara (C12)

\begin{tabular}{lcrrr}
\hline & Frequency & Percent & $\begin{array}{r}\text { Valid } \\
\text { Percent }\end{array}$ & Percent \\
\hline $\begin{array}{l}\text { Tidak } \\
\text { Berpendapat }\end{array}$ & 4 & 8.9 & 8.9 & 8.9 \\
\hline Setuju & 23 & 51.1 & 51.1 & 60.0 \\
\hline Sangat Setuju & 18 & 40.0 & 40.0 & 100.0 \\
\hline Total & 45 & 100.0 & 100.0 & \\
\hline
\end{tabular}

Tabel 20. Kondisi Penerangan (C13)

\begin{tabular}{lccrr}
\hline & Frequency & Percent & $\begin{array}{r}\text { Valid } \\
\text { Percent }\end{array}$ & Percent \\
\hline $\begin{array}{l}\text { Tidak } \\
\text { Berpendapat }\end{array}$ & 2 & 4.4 & 4.4 & 4.4 \\
\hline Setuju & 16 & 35.6 & 35.6 & 40.0 \\
\hline Sangat Setuju & 23 & 51.1 & 51.1 & 91.1 \\
\hline Total & 45 & 100.0 & 100.0 & \\
\hline
\end{tabular}


Tabel 21. Jarak Berjalan Menuju Lokasi (C14)

\begin{tabular}{lrrrr}
\hline & & & \multicolumn{2}{r}{ Cumulative } \\
\hline & Frequency & Percent & $\begin{array}{r}\text { Valid } \\
\text { Percent }\end{array}$ & Percent \\
\hline Tidak Setuju & 6 & 13.3 & 13.3 & 13.3 \\
\hline $\begin{array}{l}\text { Tidak } \\
\text { Berpendapat }\end{array}$ & 12 & 26.7 & 26.7 & 40.0 \\
\hline Setuju & 20 & 44.4 & 44.4 & 84.4 \\
\hline Sangat Setuju & 7 & 15.6 & 15.6 & 100.0 \\
\hline Total & 45 & 100.0 & 100.0 & \\
\hline
\end{tabular}

Tabel 22. Kesesuaian Tarif Parkir (C15)

\begin{tabular}{lrrrr}
\hline & & & \multicolumn{2}{r}{ Cumulative } \\
\hline & Frequency & Percent & $\begin{array}{r}\text { Valid } \\
\text { Percent }\end{array}$ & Percent \\
\hline Tidak Setuju & 1 & 2.2 & 2.2 & 2.2 \\
\hline $\begin{array}{l}\text { Tidak } \\
\text { Berpendapat }\end{array}$ & 11 & 24.4 & 24.4 & 26.7 \\
\hline Setuju & 27 & 60.0 & 60.0 & 86.7 \\
\hline Sangat Setuju & 6 & 13.3 & 13.3 & 100.0 \\
\hline Total & 45 & 100.0 & 100.0 & \\
\hline
\end{tabular}

\subsection{Statistik Inferensial}

\subsubsection{Pengujian Normalitas data}

Uji normalitas dapat dilakukan dengan memakai rumusan chi kuadrat. Seperti pada pengujian sebelumnya, maka dalam mengambil keputusan untuk pengujian normalitas data perlu diperhatikan hal berikut:

1. Hipotesis.

a. $\mathrm{H}_{0}=$ Sampel ditarik dari populasi yang mengikuti distribusi seragam, atau pelayanan parkir di pusat perbelanjaan (BSM) disukai konsumen secara merata.

b. $\mathrm{H}=$ Sampel bukan berasal dari populasi yang mengikuti distribusi seragam, atau setidaknya pelayanan parkir disalah satu pusat perbelanjaan lebih disukai dari yang lainnya.

2. Dasar pengambilan keputusan.

a. Berdasarkan perbandingan chi-square uji dan tabel.

Jika chi-kuadrat hitung < chi-kuadrat tabel, maka H0 diterima.

Jika chi-kuadrat hitung > chi-kuadrat tabel, maka H0 ditolak.

b. Berdasarkan probabilitas. 
Jika probabilitas $>0,05$, maka $\mathrm{H} 0$ diterima.

Jika probabilitas $<0,05$, maka $\mathrm{H} 0$ ditolak.

Hasil perhitungan dengan menggunakan program SPSS 11 ditunjukkan seperti pada Tabel 23.

Tabel 23. Tes Statistik Uji Normalitas

\begin{tabular}{lcc}
\hline & Tot 1 (X1) & Tot 2 (X2) \\
\hline Chi- kuadrat & 10,800 & 16,667 \\
\hline Derajat Kebebasan (df) & 8 & 14 \\
\hline Signifikansi & 0,213 & 0,274 \\
\hline
\end{tabular}

Analisis (semua alpha 5\%):

1. Chi-kuadrat hitung $\mathrm{X} 1=10,800$; Chi-kuadrat tabel $=15,5$; Chi-kuadrat hitung $<$ chikuadrat tabel, maka $\mathrm{H}_{0}$ diterima.

2. Chi-kuadrat hitung $\mathrm{X} 2=16,667$; Chi-kuadrat tabel $=23,7$; Chi-kuadrat hitung $<$ chikuadrat tabel, maka $\mathrm{H}_{0}$ diterima.

3. Probabilitas $\mathrm{X} 1=0,213>0,05$, maka $\mathrm{H}_{0}$ diterima. Probabilitas $\mathrm{X} 2=0,274>0,05$, maka $\mathrm{H}_{0}$ diterima.

Untuk pelayanan parkir di Bandung Supermall ternyata berdistribusi seragam/normal. Dari hasil pengujian di atas terlihat bahwa distribusi yang ada seragam. Tentunya hal ini tidak sesuai seperti asumsi awal penelitian, yakni populasi yang ada bersifat heterogen. Populasi yang homogen maksudnya adalah responden yang dilibatkan dalam penelitian hanya terdiri dari satu kriteria saja, tetapi sesuai dengan kebutuhan penelitian.

\subsubsection{Perhitungan Berdasarkan Nilai Rata-rata}

Perhitungan dilakukan dengan membandingkan jumlah keseluruhan skor pada masing-masing variabel dengan total responden yang ada. Masing-masing jawaban diberi skor tersendiri dimana untuk tingkat kepentingan peningkatan kualitas nilai rata-rata variabel (r) memiliki arti, yaitu: $\mathrm{r}_{\mathrm{i}} \leq 1=$ Sangat penting sekali, $1<\mathrm{r}_{\mathrm{i}} \leq 2=$ Penting sekali, $2<\mathrm{r}_{\mathrm{i}} \leq$ $3=$ Penting, $3<\mathrm{r}_{\mathrm{i}} \leq 4=$ Cukup penting, $4<\mathrm{r}_{\mathrm{i}} \leq 5=$ Tidak penting

Perhitungan kualitas pelayanan parkir di Bandung Supermall dengan menggunakan nilai rata-rata setiap variabel dapat dilihat pada Tabel 24. 
Tabel 24. Hasil Perhitungan Tingkat Kepentingan Rata-rata Setiap Variabel untuk Kualitas Pelayanan Parkir di Bandung Supermall

\begin{tabular}{|c|c|c|c|c|}
\hline $\begin{array}{c}\text { Elemen yang } \\
\text { diteliti }\end{array}$ & Variabel & $\begin{array}{c}\text { Tingkat } \\
\text { Kepentingan } \\
\text { rata-rata } \\
\text { variabel }\end{array}$ & $\begin{array}{c}\text { Peringkat } \\
\text { berdasarkan } \\
\text { elemen yang } \\
\text { diteliti }\end{array}$ & $\begin{array}{c}\text { Peringkat } \\
\text { secara } \\
\text { keseluruhan }\end{array}$ \\
\hline \multirow{2}{*}{$\begin{array}{c}\text { Kemudahan } \\
\text { parkir }\end{array}$} & B1 & 3,444 & 1 & 13 \\
\hline & B2 & 3,067 & 2 & 15 \\
\hline \multirow{2}{*}{$\begin{array}{c}\text { Kinerja petugas } \\
\text { parkir }\end{array}$} & $\mathrm{C} 3$ & 4,200 & 1 & 2 \\
\hline & $\mathrm{C} 4$ & 3,778 & 2 & 10 \\
\hline \multirow{4}{*}{$\begin{array}{l}\text { Geometrik ruang } \\
\text { parkir }\end{array}$} & $\mathrm{C} 5$ & 3,978 & 213 & 5 \\
\hline & C6 & 4,000 & & 4 \\
\hline & C7 & 3,933 & & 7 \\
\hline & $\mathrm{C} 8$ & 4,111 & 2 & 3 \\
\hline \multirow[t]{4}{*}{ Keamanan } & C9 & 4,311 & 1 & 1 \\
\hline & $\mathrm{C} 10$ & 3,956 & 3 & 6 \\
\hline & $\mathrm{C} 11$ & 3,422 & 4 & 14 \\
\hline & $\mathrm{C} 12$ & 3,867 & 1 & 8 \\
\hline \multirow[t]{2}{*}{ Kenyamanan } & $\mathrm{C} 13$ & 3,644 & 2 & 11 \\
\hline & $\mathrm{C} 14$ & 3,622 & 3 & 12 \\
\hline Tarif parkir & $\mathrm{C} 15$ & 3,822 & 1 & 9 \\
\hline
\end{tabular}

Ternyata responden merasakan kualitas keamanan parkir di Bandung Supermall merupakan pelayanan parkir yang paling memuaskan, khususnya pada saat keluar dengan pemeriksaan karcis parkir dan disesuaikan dengan kendaraan dengan nilai kepentingan ratarata sebesar 4,311.

Elemen kemudahan parkir menempati peringkat terakhir, khususnya dalam hal berputar-putar karena kesulitan mendapatkan tempat parker dengan tingkat kepentingan ratarata sebesar 3,067.

\section{KESIMPULAN}

1. Melalui dua buah pengujian, maka instrumen penelitian yang berupa angket teruji nilai kevaliditasan dan reliabilitasnya, artinya adalah semua data yang diinginkan berkaitan 
dengan pelayanan parkir telah terangkum di dalam angket dan apabila dipakai berulang kali pada waktu yang berbeda, hasil yang didapatkan masih konsisten.

2. Hasil pengujian normalitas data memperlihatkan bahwa populasi seragam dan tidak ada batasan tertentu mengenai frekuensi berkunjung seseorang ke pusat perbelanjaan untuk menggunakan jasa pelayanan parkir.

3. Pada dasarnya kualitas pelayanan parkir di pusat perbelanjaan sudah cukup baik, hal ini terbukti melalui hasil perhitungan nilai rata-rata elemen yang diuji bahwa besar tingkat kepentingan rata-rata variabel berada di atas angka

4. Pada umumnya para pelanggan sudah merasa cukup puas dengan kualitas pelayanan parkir di pusat perbelanjaan, tetapi mereka masih menganggap kualitas pelayanan tersebut cukup penting untuk ditingkatkan terutama dalam segi kemudahan parkir yang menempati peringkat terakhir dalam elemen pelayanan.

\section{REFERENSI}

1. Anwar, A., (1999), Pengenalan Ilmu Teknik Lalu Lintas, Diktat Kuliah, Jurusan Teknik Sipil Politeknik Institut Teknologi Bandung, Bandung.

2. Departemen Perhubungan, (1998), Pedoman Perencanaan dan Pengoperasian Fasilitas Parkir, Direktorat Bina Sistem lalu Lintas Angkutan Kota, Direktorat Jenderal Perhubungan Darat, Jakarta.

3. Nasution, (1982), Metode Research, Jemmars, Jakarta.

4. Singarimbun, M., Effendi, S., (1989), Metode Penelitian Survei, LP3ES, Yogyakarta.

5. Sugiyono, (2002), Statistika untuk Penelitian, CV Alfabeta, Bandung.

6. Yudhistira, B.S., (2003), Jasa Pelayanan Parkir Valet, Tugas Akhir JTS FT UGM. 